\title{
A Note on Citations
}

Like all other modern academics writing on Smith, I cite the standard Glasgow edition of his works (for bibliographic details see References). I follow the convention of labelling the individual volumes as follows.

TMS: The Theory of Moral Sentiments. Glasgow edn Vol. I. WN: $\quad$ Inquiry into . . the Wealth of Nations. Glasgow edn Vol. II in two parts.

EPS: $\quad$ Essays on Philosophical Subjects. Glasgow edn Vol. III.

LRBL: Lectures on Rhetoric and Belles-lettres. Glasgow edn Vol. IV.

$L J(A)$ : Lectures on Jurisprudence, report of 1762-3. Glasgow edn Vol V.

$L J(B)$ : Lectures on Jurisprudence, report dated 1766. Glasgow edn Vol V.

Corr. Correspondence of Adam Smith. Glasgow edn Vol VI.

In TMS and WN, I cite passages using Smith's own part and chapter divisions, as codified by the editors of the Glasgow edition. Since parts and chapters are of very different lengths, the number of symbols in a citation varies between three and four. An example of a full four-symbol citation is WN V.i.f.16. The first element (roman capital numeral) is the Book. The second element (roman lower-case numeral) is the Chapter. The third element (lower-case letter in WN, arabic numeral in TMS), where there is one, is a subdivision of Smith's into a 'Part' or an 'Article', or simply a subheading of Smith's. The fourth element (arabic numeral) is a paragraph within the next higher subdivision.

This system has become an industry standard, like the QWERTY typewriter and the VHS video recorder. Therefore no individual user has an incentive to break away. However, it does have some drawbacks, the main one being that the symbol i may either be a lower-case roman numeral or a letter. There is a WN V.i.i. That is not the introduction to Book V, Chapter $1-$ it is the ninth element of that chapter, which is in fact the Conclusion.

$L R B L, L J(A)$, and $L J(B)$ are all printed from manuscript notebooks discovered in $1895(L J(B))$ and 1958 (the others). I cite the Glasgow 
subdivisions, which give the original manuscript volume numbers in lower-case roman (for $L R B L$, which was in two volumes, and $L J(A)$, which was in six), followed by paragraph number in arabic.

The most important parts of EPS are:

- the 'History of Astronomy', cited as Astronomy with Section (roman caps) and paragraph (arabic numeral); and

- Dugald Stewart's Account of the Life and Writings of Adam Smith, Ll.D, cited as Stewart, with Section (roman caps) and paragraph (arabic numeral).

In Corr., I cite the letters by their number (using the \# symbol) or letter. The lettered correspondence comprises items discovered late in the preparation of the volume and printed at the end.

Citations from manuscripts and rare books relating to Smith in Glasgow University Library or Glasgow University Archives \& Business Record Centre are accompanied by the archive's own reference number. Other citations follow the Harvard author-date system. Citations to websites were all checked during summer or autumn 2005 and found to be live. Any reader discovering a non-functioning link is asked to kindly let me or the publishers know. 